\title{
A prospective audit of the use and costs of myelography in a regional neuroscience unit
}

\author{
P A G SANDERCOCK, $*$ M A ROBERTS, $†$ L D BLUMHARDT $\dagger$ \\ From the Department of Clinical Neurosciences, Western General Hospital, ${ }^{*}$ Edinburgh, and Department of \\ Neurological Science, $\dagger$ University of Liverpool, Mersey Regional Neurology Unit, Walton Hospital, Liverpool, \\ $U K$
}

SUMMARY A consecutive series of 397 myelograms performed in 385 patients over a six month period at the Mersey Regional Neurosciences Unit is reported. The reasons for performing the myelogram were to identify the cause of a radicular lesion in $54 \%$ of patients, a chronic spinal cord lesion in $30 \%$, an acute cord lesion in $9 \%$, suspected disease at the level of the foramen magnum $6 \%$, and for a variety of other conditions in $8 \%$. For the 385 patients undergoing a myelogram in the study period, the median interval from admission to request, request to myelography and from myelography to discharge was nought, one and three days respectively. The proportion of patients submitted to myelography by individual consultants ranged from $7 \%$ to $28 \%$. There was a two-fold variation in the delays in the time to requesting and performing myelograms. There was room for improvement in the clinical information supplied on the myelography request form. The role of ancillary investigations and their effect on myelography was unclear. Only 16 of the patients with suspected cord disease had visual evoked responses performed before myelography. Five of them had myelography after an abnormal result. The estimated annual direct cost of myelography in the unit was at least $£ 486,000$. Reorganisation might have yielded hypothetical "savings" of between $£ 30,000$ $(6 \%)$ and $£ 155,000(32 \%)$, though in practical terms these "savings" represented resources which might have been freed for use in other higher priority clinical problems within the unit, rather than true reductions in monetary cost.

Until fairly recently, clinicians who investigated patients with diseases of the spinal cord and spinal roots relied on careful clinical assessment aided by plain radiography, examination of the CSF and myelography using oil-based media. The advent of less toxic water-soluble contrast media has allowed clinicians to perform myelography in patients with less clearly defined clinical problems. Further changes in clinical practice are likely to follow the arrival of computed tomography (CT) of the spine and CT myelography (CTM).' Magnetic Resonance Imaging (MRI) of the spinal cord ${ }^{2}$ may lead to a dramatic reduction in the need for myelography and, in certain clinical situations, may completely replace traditional

Address for reprint requests: Dr P A G Sandercock, Department of Clinical Neurosciences, Western General Hospital, Crewe Road, Edinburgh EH4 2XU.

Received 21 June 1988 and in revised form 24 April 1989. Accepted 18 May 1989 imaging methods. Clinicians can avoid invasive investigations by using the visual evoked response (VER) or CSF oligoclonal banding results in patients with spinal cord disease. As 700 or so myelograms are performed each year in this unit (fig), we wanted to examine our own clinical practice in patients with diseases of the spine and spinal cord, including our use of the other investigative methods, and the financial costs of myelography. We wanted to identify deficiencies in the organisation of a routine clinical test, and to provide a baseline for assessing the impact of new alternative procedures such as MRI. We wanted, as every audit should, to identify the reasons for any differences in clinical practice (and costs) between clinicians. $^{34}$

\section{Methods}

The Mersey Regional Neurology Unit is attached to the Walton District General Hospital (DGH). At the time of the study there were five consultants in adult neurology, one 
consultant in paediatric neurology and five consultant neurosurgeons. The Departmental catchment area extends from the southern tip of Gwynedd (south of Bangor) in North Wales to Southport and Ormskirk to the North, and includes a population of more than three million people. The study was designed to:

(1) Identify all patients undergoing myelography or radiculography in a six-month period from daily examination of the x-ray Department Day Book (in which basic details of every patient undergoing radiological procedures are recorded).

(2) Examine the spectrum of clinical conditions in patients submitted for myelography, the type of myelographic examination required, and the quality of information given by the clinician to the radiologist.

(3) Compare the area specified on the x-ray request form and the anatomical region actually examined. The radiographs were reviewed weekly with a radiologist.

(4) Examine the use of ancillary investigations, such as VER and CT scans.

(5) Estimate the costs associated with myelography:

(a) duration of in-patient stay;

(b) x-ray Department costs;

(c) any disparity between our own costing and official NHS costings.

(6) Check the patients' medical records, the radiologists $\mathrm{x}$-ray reports and the final discharge summary on every patient for possible discrepancies.

Using data from the clinical notes and the x-ray report, we determined whether the area to be examined on the myelogram was appropriate to the clinical problem. This determination was blind to the result of the myelogram, to avoid bias.

The estimates of the costs to the $x$-ray Department were compiled by the Superintendent Radiographer using prices for materials effective at the end of the Study Period. Assumptions were made as follows:

(1) A fixed number of disposable items including contrast medium would be used for each procedure.

(2) The cost of films used was estimated from the mean number of films per procedure as counted by the Study Team.

(3) Staff costs assumed that one Senior Radiographer was dedicated full-time to myelography and a dark-room Technician spent one fifth of her time processing myelogram x-ray films. Radiologists salaries were excluded from the costings since they are not included in standard NHS costings.

(4) Depreciation was calculated assuming a 10 year write down on capital $\mathbf{x}$-ray and processing equipment.

(5) Costs of cleaning, lighting, heating, electricity, rates or building costs were not included.

\section{Analysis}

The data were entered and stored on computer, using dBaselI (copyright Ashton-Tate). Tabulations were prepared using dBaseII and BMDP. ${ }^{5}$ Confidence intervals were calculated using the exact method for the confidence interval of a proportion. Means were compared using two independent sample $t$ test procedures.

We calculated the costs associated with the inpatient stay using the following assumptions:

(1) A hospital bed-day cost of $£ 130$.
(2) The number of days in hospital for each patient assumed that all patients would be discharged on the day following myelography. A patient admitted on 11 November 1985 for a myelogram on 13 November 1985 would be counted as spending $2+1=3$ days in hospital. This method avoids attributing costs of unrelated conditions to the procedure of myelography itself.

(3) The annual cost was estimated by multiplying the total number of myelograms performed in 1986 by the average cost per procedure for patients examined during the six month study period.

(4) The annual savings in costs associated with bed occupancy were calculated by multiplying the estimated average saving per patient during the study period by the total number of myelograms in 1986.

\section{Results}

Three hundred and eighty-five patients had a first myelogram during the six month study period. Twelve $(3 \%)$ underwent a second myelogram within the study period, making a total of 397 myelograms in six months. Twenty-eight of the 385 patients had previously had a myelogram performed in the three months before the study began (see below).

All results below will refer to the 385 patients undergoing their first myelogram in the study period, unless stated otherwise.

The source of patients referred for myelography was: a routine admission to the Neuroscience Unit in $318(83 \%)$; an urgent transfer from another hospital in 43 (11\%); an urgent direct referral from a General Practitioner in $13(3 \%)$. Eleven $(3 \%)$ were patients on a medical or orthopaedic ward in Walton DGH.

Table 1 gives the clinical diagnosis made before the myelogram. Many patients had several neurological problems or several possible explanations for their clinical history and physical signs. Table 2 gives the conditions present in patients referred for myelography by neurologists and neurosurgeons.

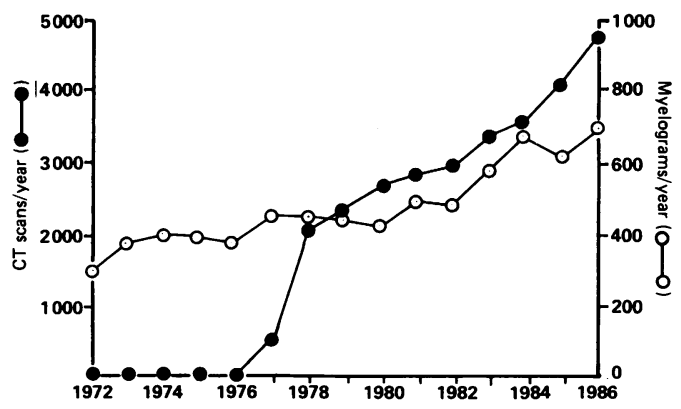

Fig The number of CT scans of the head and myelograms performed each year in the Department of Neurosciences, Walton Hospital, Liverpool between 1972 and 1986. 
Table 1 Clinical diagnosis before myelography

\begin{tabular}{|c|c|c|c|}
\hline & $\begin{array}{l}\text { Only } \\
\text { feature }\end{array}$ & $\begin{array}{l}\text { Other } \\
\text { features } \\
\text { present } \\
\text { as well }\end{array}$ & Total \\
\hline $\begin{array}{l}\text { Radicular or LMN lesion(s) } \\
\text { Chronic cord lesion (present }\end{array}$ & 177 & 32 & 209 \\
\hline & 88 & 26 & 114 \\
\hline & 28 & 5 & 33 \\
\hline $\begin{array}{l}\text { lesion } \\
\text { Suspected dysraphism } \\
\text { Cervical or lumbar pain* } \\
\text { Suspected syrinx } \\
\text { Other }\end{array}$ & $\begin{array}{r}13 \\
1 \\
5 \\
4 \\
24\end{array}$ & $\begin{array}{r}10 \\
11 \\
6 \\
7 \\
6\end{array}$ & $\begin{array}{l}23 \\
12 \\
11 \\
11 \\
30\end{array}$ \\
\hline
\end{tabular}

LMN = lower motor neuron.

*Pain restricted to the cervical or lumbar region with no radiation.

Some patients had more than one lesion.

\section{Area selected for myelography}

In 64 patients, the $x$-ray request form stated only "myelogram", without specifying a particular area of interest. In 10 patients, the space for the type of $x$-ray procedure requested was either left blank or the request form was missing. The area requested was judged inappropriate in $34(11 \%, 95 \%$ confidence intervals 8-15\%).

\section{Repeat myelograms}

Twenty-eight patients had had a myelogram performed within a three month period before the study began. The myelogram was repeated in our Unit because the myelogram had been performed at another hospital in the region and was inappropriate or technically inadequate (16 cases), because of recurrent symptoms (6), to obtain further detail of a known lesion (3), or for other reasons (3).

Twelve of the 385 patients undergoing a first ever myelogram during the study had to have the examination repeated (patients who had a cervical and lumbar myelogram as a single procedure to delineate the upper and lower extent of a complete spinal block were not counted as having repeated myelograms). The reason for repeating the myelogram was because the first myelogram was technically unsatisfactory in four, to delineate a block or obtain further detail of a lesion in two, because the incorrect anatomical area had been requested for the first myelogram in two, because the correct area had been requested but the radiologist had examined an inappropriate area in two, and to try to get contrast into a suspected syrinx in one. Important unexpected pathology was discovered in one of the twelve patients, a man with a mild spastic paraparesis and sensory disturbance in the legs. His first myelogram had been restricted to the thoracic region and was normal. Repeat myelography of the cervical region showed an arteriovenous malformation of the cervical cord, proven by angiography.

\section{Ancillary investigations}

Twenty nine per cent had CT scans of the head performed before or during the period spent in hospital for myelography. One scan showed multiple cerebral metastases in a patient with a cauda equina syndrome; the remaining abnormalities included cerebral atrophy, mild communicating hydrocephalus, cerebral infarction, white matter low-attenuation and/or lesions compatible with white matter demyelination; the diagnostic contribution of the CT scan in the latter cases was hard to quantify. VER were only counted in patients whose results were known to the clinician before the myelogram $(n=16)$. Five of the patients in this group had a myelogram after an abnormal VER had been recorded.

\section{Costs}

The estimated costs for the radiological procedure and bed occupancy are given in tables 3 and 4 . The median number of $\mathrm{x}$-ray films used per investigation was 11 (mean 11.3, range 3-26). Three hundred and seventythree myelograms were performed during normal working hours and 12 were performed outside working hours. The standard NHS cost was calculated at 60 radiographic cost units $\times 66$ pence per unit $=£ 39.60$.

\section{Variations between clinicians}

Case load: There was considerable variation in several aspects of myelographic practice, both between individuals and between the neurologists and neurosurgeons as two separate groups (table 5). We explored the variation in myelography as a proportion of total

Table 2 Clinical diagnosis before myelography*

\begin{tabular}{|c|c|c|c|c|c|}
\hline Myelogram requested by & $\begin{array}{l}\text { Radicular } \\
\text { lesion }\end{array}$ & $\begin{array}{l}\text { Chronic } \dagger \\
\text { cord lesion }\end{array}$ & $\begin{array}{l}\text { Acute } \ddagger \\
\text { cord lesion }\end{array}$ & $\begin{array}{l}\text { Foramen } \\
\text { magnum lesion }\end{array}$ & Dysraphism \\
\hline $\begin{array}{l}\text { Neurologist }(n=209) \\
\text { Neurosurgeon }(n=167) \\
\text { Other physician/surgeon }(n=9) \\
\text { Total }\end{array}$ & $\begin{array}{r}89 \\
112 \\
8 \\
209\end{array}$ & $\begin{array}{r}79 \\
34 \\
1 \\
114\end{array}$ & $\begin{array}{l}16 \\
\frac{17}{33}\end{array}$ & $\begin{array}{r}17 \\
\frac{6}{23}\end{array}$ & $\begin{array}{r}5 \\
\frac{7}{12}\end{array}$ \\
\hline
\end{tabular}

$\mathrm{n}=$ Numbers of patients.

*Each patient could have more than one clinical indication.

tSymptoms of cord lesions present for more than one month at the time myelogram requested.

† Symptoms of cord lesion present for less than or equal to one month at the time myelogram requested. 
Table 3 Cost of radiological procedures per myelogram (pounds)

\begin{tabular}{ll}
\hline Films & \\
Contrast & \\
Processing & \\
Chemicals & 0.55 \\
Salary & 1.96 \\
Equipment depreciation & $\underline{1.14}$
\end{tabular}

Disposables

Staff

Radiography (full time)

Equipment

Depreciation

Service contract

28.00

$\frac{11.40}{72 \cdot 37}$

NHS standard charge

$39 \cdot 60$

*This is an underestimate, since no allowance has been made for the small additional cost of overtime pay for radiographers performing the 12 myelograms performed out of normal working hours.

case load between individual consultants and between neurologists and neurosurgeons, as two groups by calculating for each consultant:

percentage $=\frac{\begin{array}{l}\text { number of patients undergoing } \\ \text { myelography in the study period }\end{array}}{\begin{array}{l}\text { number of patients discharged from } \\ \text { the ward in study period }\end{array}}$

We used a chi square test to assess the significance of differences between individual neurologists $\left(\chi_{4}^{2}=\right.$ $10.78, p=0.027)$ and between individual neurosurgeons $\left(\chi_{4}^{2}=35.49, p=0.00000047\right)$ both of which strongly suggest that the variation in proportion of patients undergoing myelography between individual consultants was not due to chance alone. To assess the difference in proportion of patients undergoing myelography between neurologists and neurosurgeons, an independent two sample $t$ test was used to compare the mean proportions. There was a nonsignificant trend towards a higher proportion of neurological patients undergoing myelography (21 $v$ $12 \%$ respectively $=0.075$ ).

Case Mix: There were marked differences between consultants in the type of patients undergoing myelography (or case mix). The simplest assessment of a consultants' case-mix was the proportion of his patients undergoing myelography for a pure radicular lesion. In general, such patients do not require complex screening tests before myelography, such as evoked potentials or CT scanning of the head, and it is feasible to request the myelogram as soon as the patient is admitted to hospital. The $25 \%$ difference in proportion of patients undergoing myelography for pure radicular lesions between neurologists and neurosurgeons of $(95 \% \mathrm{CI}$ of the difference- 16 to $35 \%$ difference) was highly significant $(p=0.0005)$. In other words, the case-mix of neurological and neurosurgical patients undergoing myelography was significantly different.

The marked difference in case-mix between neurologists and neurosurgeons probably accounted for most of the differences between neurologists and neurosurgeons with respect to delays in requesting and performing myelography. Neurosurgeons requested a significantly higher proportion of myelograms on the day the patient was admitted to hospital and a significantly higher proportion of neurosurgical patients had the myelogram performed within 48 hours.

\section{Discussion}

To the best of our knowledge, this is the first audit of the use of myelography in an adult neurological or neurosurgical unit in the United Kingdom. We wanted to examine the use of the investigation because of recent changes in the assessment of spinal cord disease, the availability of newer ancillary investigations and because of increasing pressure to reduce the costs of current practice.

Table 4 Estimated annual cost in pounds of myelography and potential "savings" in bed occupancy from different organisational policies

Six month cost in 385 patients

Cost

Hospital inpatient stay

Between admission and request $\quad 130 \times 815=106,000$

Between request and myelogram $\quad 130 \times 661=86,000$

Between myelogram and discharge ${ }^{*} \quad 130 \times 385=50,000$

Radiography costs (see table 7)

$385 \times 72 \cdot 37=28,000$

Average cost per patient $\quad 270,000 \div 385=700$

Estimated Annual Cost

$700 \times 694=486,000$

Potential "Savings" in Hospital Bed-day Costst

If all myelograms requested one day earlier

If all myelograms requested on day of admission

Over study Estimated period annual

If all myelograms performed one day earlier

$17,000 \quad 30,000$

If all myelograms performed on day

$56,000 \quad 101,000$

of request

46,000

82,000

86,000

155,000

* See methods section, assuming all patients discharged on the day following myelogram. Cost $=£ 130$ per bed-day $\times$ number of bed days.

†"Savings" in the sense that the bed occupancy associated with myelography would be reduced, reduction in overall cost for the Neuroscience Unit would only be achieved if the vacated beds were left empty. All figures are rounded to the nearest $£ 1,000$. 
Table 5a Variations between consultants in case load, case mix and delays in requesting and performing myelograms

\begin{tabular}{|c|c|c|c|c|c|c|}
\hline \multirow[b]{2}{*}{ Number } & \multicolumn{3}{|l|}{ Case load } & \multirow{2}{*}{$\begin{array}{l}\text { Case-mix } \\
\% \text { of all } \\
\text { myelograms for } \\
\text { pure radicular } \\
\text { lesion }\end{array}$} & \multicolumn{2}{|l|}{ Delays } \\
\hline & $\begin{array}{l}\text { No of patients } \\
\text { having } \\
\text { myelograms in } \\
\text { study period (a) }\end{array}$ & $\begin{array}{l}\text { No of patients } \\
\text { discharged in } \\
\text { study period }(b)\end{array}$ & $\begin{array}{l}\text { Percentage } \\
\text { a/b } \times 100 \\
(95 \% \mathrm{CI})\end{array}$ & & $\begin{array}{l}\text { \% of all } \\
\text { myelograms } \\
\text { requested on day } \\
\text { of admission }\end{array}$ & $\begin{array}{l}\% \text { of all } \\
\text { myelograms } \\
\text { performed within } \\
2 \text { days of request }\end{array}$ \\
\hline $\begin{array}{l}1 \\
2 \\
3 \\
4 \\
5\end{array}$ & $\begin{array}{l}55 \\
54 \\
39 \\
30 \\
25\end{array}$ & $\begin{array}{l}215 \\
192 \\
230 \\
168 \\
174\end{array}$ & $\begin{array}{ll}26 & (20-32) \\
28 & (22-35) \\
17 & (12-22) \\
18 & (12-24) \\
14 & (9-20)\end{array}$ & $\begin{array}{l}45 \\
43 \\
49 \\
37 \\
40\end{array}$ & $\begin{array}{l}46 \\
56 \\
59 \\
67 \\
48\end{array}$ & $\begin{array}{l}44 \\
44 \\
54 \\
47 \\
52\end{array}$ \\
\hline \multicolumn{3}{|c|}{$\begin{array}{l}\text { Mean ( } 95 \% \text { confidence interval) for five } \\
\text { neurologists }\end{array}$} & $21 \quad(14-28)$ & 43 & 55 & 48 \\
\hline
\end{tabular}

Table 5b

\begin{tabular}{|c|c|c|c|c|c|c|}
\hline \multicolumn{7}{|c|}{ Neurosurgical consultant } \\
\hline Number & \multicolumn{3}{|l|}{ Case load } & $\begin{array}{l}\text { Radicular } \\
\% \text { of all } \\
\text { myelograms for } \\
\text { pure radicular } \\
\text { lesion }\end{array}$ & \multicolumn{2}{|l|}{ Delays } \\
\hline \multirow{2}{*}{\multicolumn{3}{|c|}{$\begin{array}{l}\text { Mean ( } 95 \% \text { confidence interval) for five } \\
\text { neurologists } \\
\text { Difference in means between neurologists } \\
\text { and neurosurgeons ( } 95 \% \text { confidence interval) } \\
\text { p for difference }\end{array}$}} & $12(4-21)$ & 68 & 79 & 68 \\
\hline & & & $\begin{array}{l}* 9(-1-18) \\
0.075\end{array}$ & ${ }_{0.0005}^{25}(16-35)$ & $\begin{array}{c}24(9-39) \\
0.0062\end{array}$ & $\begin{array}{l}20(5-35) \\
0.018\end{array}$ \\
\hline
\end{tabular}

* Means compared with two independent sample $t$ tests.

This table excludes 15 patients: six orthopaedic, six paediatric neurology patients, one medical, one general surgical and one pain clinia patient.

Case load: The consultants are ranked by speciality and by the number of first myelograms they requested in the study period. The number of patients discharged from the unit under their care during the study period appears in the next column. The percentage is the percentage of all discharges undergoing myelography and the figures in parentheses are the $95 \%$ confidence intervals. Comparison of the numbers of patients undergoing myelography within each speciality is $\chi^{24}=10.78, p=0.029$ for neurologists and $\chi^{24}=35.49$, p $=0.00000047$ for neurosurgeons.

Type: The percentage is the number of patients undergoing myelography for a pure radicular lesion/total number of myelograms for that consultant.

Delays: The percentage of patients in whom the myelogram was requested on the day of admission and the percentage of patients in whom the myelogram was performed within two days of the request.

The first aspect of practice we wanted to assess was the range of clinical conditions investigated by myelography. Data from the era of oil-based x-ray contrast media suggested that $18 \%$ of orthopaedic surgeons and 3\% of neurosurgeons regarded myelography as "too risky" for the routine investigation of lumbar disc prolapse. ${ }^{6}$ Our data suggest that, as a result of its relatively low toxicity, water-soluble myelography is now used more frequently and in a less well defined range of conditions than before.

Water soluble contrast disperses rapidly, so it is important to identify beforehand the suspected site of the spinal lesion so that this area may be examined appropriately without using large doses of contrast. In this series the $\mathrm{x}$-ray request form did not specify an area of interest in $74 / 385$ patients $(19 \%)$. Amongst the 311 patients where an area of interest was specified, we considered the area "inappropriate" in $34(11 \%)$ either because the area specified was too extensive or not extensive enough. Patients whose myelograms we deemed "not extensive enough" did not always have further myelography, so we cannot be certain that the apparent omission was detrimental to the patient's well-being. One patient with a normal thoracic myelogram was later found to have an arteriovenous malformation in the cervical cord. Some of these apparent errors occurred because the request forms were completed by inexperienced junior staff who did not understand the potential limitations of the technique and/or failed to describe the nature of the 
clinical problems clearly enough. This could be avoided if consultants specify the area(s) of interest when putting the patient on the waiting list. It is likely that similar errors occur in other neurological units and we would suggest that this is a simple way of reducing both the risk of missing treatable lesions and the number of myelograms which are not anatomically appropriate to the clinical problem.

The use of CT scanning prior to myelography is of interest. Although we do not know the exact number of cases in which the CT scan showed a lesion such as a parasagittal meningioma or hydrocephalus, thus avoiding the need for a myelogram, a retrospective review of the unit records suggested that unsuspected parasagittal meningiomas were found in less than one in 5,000 cases coming to myelography. The use of CT and MRI scanning of the spine was restricted at the time of the audit, as the equipment had only recently been installed.

McDonald and Halliday ${ }^{7}$ and more recently $\mathrm{Kempster}^{8}$ have suggested that myelography for suspected isolated spinal cord lesions could be avoided if the VER was abnormal and the CSF showed a raised cell count or the presence of oligoclonal banding and a CT brain scan and plain radiograph of the spine were normal. ${ }^{78}$ Our results suggest that in this unit the VER is infrequently used to avoid myelography; only 16 of 115 patients with suspected chronic spinal cord lesions had a VER result available before the myelogram, and myelography was performed in the presence of an abnormal result in five of these. However, in these five patients, another abnormality was present which might have accounted for the abnormal VER in three, and in two the VER was the only abnormality suggesting disease above the level of the foramen magnum. This conservative approach may reflect the disturbing reports of abnormal VER associated with compressive lesions. ${ }^{9}$

Our third main area of interest was the cost of myelography, the accuracy of NHS charges and the possibility of achieving savings without adversely affecting clinical practice. NHS costings differ from our own, although the difference is smaller if estimates for depreciation of equipment are removed from our figures. The discrepancies highlight the need for accurate, up-to-date, locally-relevant cost data in the formulation of clinical budgets. Of importance to clinicians are the costs related to the in-patient stay. Some delay before myelography is performed is inevitable, particularly when cord lesions are suspected, since the clinician may wish to know the results of other tests before proceeding. In this series, such tests were generally performed as an outpatient. Some of the delays arose because junior clinical staff were not aware of planned closures of the myelographic suite for maintenance. Other delays arose because of equipment failure.
This audit revealed quite marked variation in length of stay - and hence cost - between consultants. To see if this represented important differences in efficiency (and appropriate use of resources) or merely differences in case mix between consultants, we examined several factors. There was considerable variation between consultants in the proportion of their patients submitted to myelography. There was a four-fold difference both in the absolute numbers and in the proportion of patients undergoing myelography. It was interesting to note a variation in the proportion of patients in whom the myelogram was requested on the day of admission. Most of the variation was accounted for by the proportion of patients with relatively straightforward clinical problems; in general, for a given consultant, the higher the proportion of his patients with pure radicular problems, the higher the proportion in whom the request was submitted early. In general, patients in whom the request for myelography was delayed several days after admission had complex neurological problems which required noninvasive tests (such as CT scanning, VER) before a decision whether to perform a myelogram could be made. Some consultants were able to organise such tests on an out-patient basis whereas others, working in remote clinics, had to admit patients to the unit for these screening tests.

Although the audit identified wide variations in clinical practice and organisation, many factors came into play to account for the variability. Nevertheless, $18 \%$ of patients waited two days or more before their myelogram was requested. If all myelograms had been requested one day earlier in each case, the estimated annual "saving" would have been $£ 30,000$. Similarly, there were delays in performing myelograms. If the examination had been performed one day earlier in each case, the estimated annual saving would have been $£ 82,000$. However, these "savings" are difficult to assess, since the "free" bed days generated would increase patient turnover and therefore costs. The "savings" should thus be regarded as resources which might be reallocated to clinical problems of higher priority, rather than potential reductions in monetary cost. A partial solution to some of the problems of delays would be to set up a programmed investigation unit. This has been implemented while this publication was in preparation. These analyses highlight the difficulties in managing clinical budgets and emphasise the need to assess the effects of case mix before attributing high costs for a particular clinician to "inefficiency".

The introduction of MRI scanning in some units has substantially altered the management of patients with suspected spinal cord disease. ${ }^{1011}$ The introduction of MRI in Bristol has coincided with a $50 \%$ reduction in the number of myelograms performed, with substantial savings in discomfort and inconvenience to the 
patient; detailed costings were not available, so it is not yet clear whether MRI, by substituting for myelography, will reduce the total cost of investigating patients with spinal cord disease. This study and that from Bristol will provide a useful baseline against which to compare the cost-effectiveness of future changes in clinical practice. Nonetheless, since even CT head-scanning is only available in $40 \%$ of health districts, ${ }^{12}$ it is likely that MRI scanning will not be freely available in all health districts for many years to come, and myelography will continue to be an important but costly necessity for the foreseeable future.

We thank the Neurologists and Neurosurgeons in the Department for allowing us to study their patients; the staff of the Neuroradiology Department for help at all stages of the Study; Ms Lesley Shaw-Giles for help with assessing the costs of myelography; Mrs Deirdre Harrington for helping with data collection and for providing secretarial support and Ms Lorna Bingham for typing the manuscript; Mr K T Jones, South Sefton DHA for providing data on discharges from the unit; Professor Robin Roberts, Mr Harvey Nelson and Ms Eunice Grover-Oscar (McMaster University) for help with the statistical and computational aspects of the study.

This project was supported by Grant No. 527 from the Mersey Regional Health Authority. The analyses and the manuscript were prepared during a Visiting Professorship in the Department of Epidemiology and Biostatistics at McMaster University, Canada.

\section{References}

1 Barrow DL, Wood JH, Hoffman JC. Clinical indications for computer-assisted myelography. Neurosurgery 1983;12:47-57.

2 von Einsiedel HG, Stepan R. Magnetic resonance imaging of spinal cord syndromes. Eur J Radiol 1985;5 127-32.

3 Sackett D, Haynes RB, Tugwell P. Epidemiology: A basic Science for Clinical Medicine. Toronto: Little Brown \& Co, 1985.

4 Feeny D, Guyatt G, Tugwell P. Health care technology: effectiveness, efficiency and public policy. Montreal: Institute for research on public policy, 1986.

5 Dixon WJ (ed). BMDP Statistical Software. Berkeley: University of California Press, 1985.

6 Le Vay D. A survey of surgical management of lumbar disc prolapse in the United Kingdom and Eire. Lancet 1967;i:1211-4.

7 McDonald WI, Halliday AM. Diagnosis and classification of multiple sclerosis. Br Med Bull 1977;33:4-8.

8 Kempster PA, Iansek R, Balla JI, Dennis PM, Biegler B. Value of visual evoked response and oligoclonal bands in cerebrospinal fluid in diagnosis of spinal multiple sclerosis. Lancet 1987; i:769-70.

9 Blumhardt LD, Barrett G, Halliday AM. The pattern evoked potential in the clinical assessment of undiagnosed spinal cord disease. In: Courjon J, Maugiere F, Revol M, eds. Advances in Neurology: Clinical Applications of Evoked Potentials in Neurology. New York Raven Press, 1982;32:463-71.

10 Miller D, McDonald WI, et al. MRI of the brain and spinal cord in patients with isolated non-compressive spinal cord syndrome. Ann Neurol 1987;22:714-23.

11 Thomson JLG. Experiences at the new magnetic reson ance imaging centre in Bristol. $\mathrm{Br} J$ Radiol 1989 62:134-7.

12 Langton-Hewer R, Wood VA. The distribution of CT scanning facilities in the UK. Br Med J 1989:298: 1219-30. 